\title{
7. ON ESTABLISHING AN INTERNATIONAL SERVICE FOR COMETARY OBSERVATIONS AND EPHEMERIDES
}

\author{
M. P. CANDY \\ Perth Observatory, Bickley, Western Australia
}

I agree entirely that there is a need for such a service. As the proposal has come from the Institute for Theoretical Astronomy, is it intended that the service should be organized from there? Consideration should be given to having subsidiary centres with identical information available on request - as for the double-star service.

The service should:

(1) Publish all ephemerides: there is not room for this on the IAU Circulars.

(2) Publish all positions: the IAU Circulars are not suitable for extended series of observations.

(3) Remind individual observers when a comet is accessible and in need of observation.

(4) Encourage observers to communicate positions promptly.

(5) Actively collect all ephemerides and observations from the current literature, in case they have not been communicated.

(6) Provide orbit investigators with positions on request, saving them the trouble of searching the literature.

The service could regularly publish references to all papers with relevance to comets (including physical and spectroscopic research) with brief abstracts, if possible.

Comet positions obtained at the Perth Observatory are all sent to the IAU Bureau, prior to publication in our Communications. We can easily send a copy to another centre at the same time. We would, in any case, always supply positions to investigators who asked for them. 